\title{
Modal Analysis of Quill Shaft in Turbo-generator Unit Based on SolidWorks
}

\author{
Dr. Fares. Q. Yahya \\ Fyahya2018@uomosul.edu.iq
}

Department of Mechatronics Engineering, University of Mosul

Received: 8-5-219

Accepted: 20-8-2019

\begin{abstract}
The main goal of this work is to carry out a numerical modal analysis of a Quill shaft of turbo-generator unitaffiliate to Mosul gas turbine station, using a trail version of popular finite element analysis software SolidWorks. The main function of Quill shaft is to protect the turbo-generator unit against overloads due to electrical network faults. The high flexibility of this shaft makes it capable of absorbing high displacements of resonance phenomena. This analysis is essentially needed to study the effect of transient loads applied to Quill shaft of turbo-generator unit under severe loading conditions such as electric network disturbances. The first five values of critical frequencies and mode shapes of axial, bending, and torsional vibrations were studied and analyzed. Each mode has been isolated separately by applying a special type of boundary conditions (restraints) available in program. The three types of natural frequencies have been found and reported. It was observed that the fundamental values of each three types of natural frequencies are relatively high and out of the range of Quill shaft operating speed. Finally, it has been concluded from all analyses that Quill shaft under consideration is safe from the stand point of modal analysis. The results show that the Quill shaft is not running at any of each three types critical speeds. Therefore, the resonance phenomenon for all three types of vibrations can not be happened no matter how high the amount of transient load applied.
\end{abstract}

Keywords:

SolidWorks; Finite element method; Turbo-generator unit; Natural frequency; Modal analysis; Quill shaft; Simulation.

https://rengj.mosuljournals.com

Email: alrafidain_engjournal@umosul.edu.iq

\section{INTRODUCTION}

S. M. J. Ali, Z. Y. Mohammad and F. Q. Yahya [1] developed a model, Fig.1, for actual turbogenerator unit of Mosul gas turbine station and governing equations of this model has been formulated to estimate their respective parameters. The turbo-generator unit shown in Fig.1, is exposed to high axial, bending, and torsional oscillations due to high disturbancesinducedin the electrical grid during the connection of the generator unit to that grid. The main reasons of these faults are: the shortcircuit, open-circuit, and sudden load changes. Inaddition, the outdoor parts of the electrical

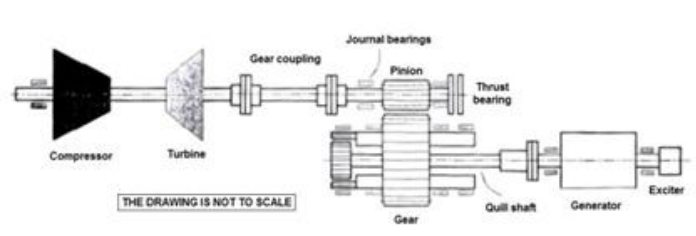

Fig.1 Turbo-generator unit

system (overhead lines, electrical towers, circuit breakers,....etc)experienced to different types of severe atmospheric conditions like ice, winds, moisture, ....etc, may play an important role in causing these types of faults. 
Qing He and Dongmei Du [2] showed that the coupling interaction between electrical network faults and torsional vibrations makesshaft of turbine-generator unitvibrate. Therefore, alternating torsional stresses due toresonate torsional vibrations. Also, when any type of faults occurs in the grid, the electromagnetic torque between stator and rotor changes rapidly. As a result, torsional vibrations of shaft occur, alternate shear stresses due to these vibrations decrease the shaft life, and may be break the shaft.

For this reason, it becomes important to compute and analyze the natural or resonatefrequencies and their corresponding mode shapes of all three types of vibrations(axial, bending, and torsional) agitated by the faults of electrical network, in order to obviate and stop disastrous accidents.

The present work is related to Mosul gas turbine station which contains multi turbo-generator units for producing electrical power. The most important and critical part of the turbo-generator unit is the Quill shaft. The purpose of Quill shaft is to connect the gearbox reducer with the generator as shown in Fig.2. Its main function is to work as a mechanical fuse for the unit to protect it against overloads and electrical faults and disturbances. The high axial, bending, and torsional flexibility owned by Quill shaft material make it deformed or brake before any other part of the unit because of its high capacity to absorb the induced large axial, bending, and torsional displacements.

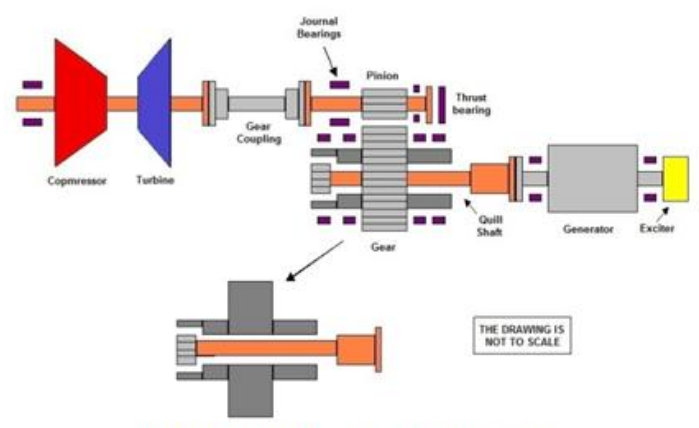

Fig.2 Quill shaft configuration

\section{Objectives of the present work}

The main goal of the present work is to find the values of resonate natural frequencies of the Quill shaft for three conditions: axial, bending and torsional and its corresponding mode shapes, by using numerical method (Finite element method) and compare them with the forced frequency (actual operating speed of the shaft).If one or more of these natural frequencies is located within the value of operated speed of the shaft, then, it is said that the shaft is in resonance condition, the case that should be avoided in the initial or early design stages.However, in this case, a redesign or improved design of Quill shaft should be introduced. This step may be carried out in the future work.

\section{MODAL ANALYSISTHEORY}

\subsection{Basic theory of modal analysis}

Yichang Liu, ChunlinTian, Tao Liu, and Fanwu Kong [3] defined the modal analysis as a numerical technique to calculate the characteristics ofstructure. The vibration characteristics of any structure including critical frequency and mode shape.

Li Cheng and Hongguang Wang [4] stated that the critical frequency and mode shape considered the two significantfactors on the dynamic properties of any mechanical structure, which are played an important role in the design of the structural system for vibration application. Both of them depend on the mass and stiffness properties of the structure. In addition, the damping has loweffect on thecritical frequency and mode shape, therefore, the damping coefficient can be cancelled in the modal analysis. For a linear system of free vibrations, thedifferential equationscan be summarized in a matrix form[5],

$\mathbf{M X}+\mathbf{C} \dot{\mathbf{X}}+\mathbf{K X}=\mathbf{0}$

Where

$\mathbf{M}$ is themass matrix ( $\mathrm{n} \times \mathrm{n}$ )

$\mathbf{K}$ is the stiffness matrix ( $\mathrm{n} \times \mathrm{n}$ )

$\mathbf{X}$ is the n-dimensional column vector of generalized coordinates.

The general form of the differential equations for a free vibrations of a linear undampedn-degree of freedom system is

$\mathbf{M} \ddot{\mathbf{X}}+\mathbf{K X}=\mathbf{0}$ 
The solution of equation (2) can be givenin the form

$\mathbf{x}(\mathrm{t})=\mathbf{X} \mathrm{e}^{\mathrm{i} \omega \mathrm{t}}$

Where $\omega$ is the vibration frequency and $\mathbf{X}$ is an ndimensional vector of mode shape.

The valuesof $\omega$ such that equation (3) is a solution of equation (2) are called the natural frequencies. Each natural frequency has at least one corresponding mode shape.

(2) leads to

Substitution of Equation (3) into Equation

$\left(-\omega^{2} \mathbf{M X}+\mathbf{K X}\right) \mathrm{e}^{\mathrm{i} \omega \mathrm{t}}=0$

Since $e^{i \omega t} \neq 0$, for each real value of $t$,

$-\omega^{2} \mathbf{M X}+\mathbf{K X}=\mathbf{0}$

The mass matrix Mis nonsingular, and thus $\mathbf{M}^{-1}$ exists. Multiplyingequation (5) by $\mathbf{M}^{-1}$ and rearranging gives

$\left(\mathbf{M}^{-1} \mathbf{K}-\omega^{2} \mathbf{I}\right) \mathbf{X}=0$

Where $\mathbf{I}$ is the identity matrix ( $\mathrm{n} \times \mathrm{n})$.

Equation (6) is the matrix form of a systemof nsimultaneous linear algebraic equations. Applying Cramer's rule to obtain the solution for the jth component of $\mathrm{X}, \mathrm{Xj}$, as

$\mathrm{Xj}=\frac{0}{\operatorname{det}\left|\mathbf{M}^{-1} \mathbf{K}-\omega^{2} \mathbf{I}\right|}$

Thus the solution $(\mathbf{X}=\mathbf{0})$ is obtained unless

$\operatorname{det}\left|\mathbf{M}^{-1} \mathbf{K}-\omega^{2} \mathbf{I}\right|=0$

Hence, $\omega^{2}$ must be an eigenvalue of $\mathbf{M}^{-1} \mathbf{K}$. The mode shape is the corresponding eigen vector.Natural frequencies of multi-degree of freedom systems are computed as the quadratic roots of the eigenvalues of $\mathbf{M}^{-1} \mathbf{K}$, i.e.,

$\omega_{\mathrm{n}}=\sqrt{\frac{\mathbf{K}}{\mathbf{M}}}$

Similarly, the equation of the angular motioncan be obtained by the same way [6]:

$\mathbf{J} \ddot{\theta}+\mathbf{K}_{\mathbf{t}} \boldsymbol{\theta}=\mathbf{0}$ which can be seen to be comparable to equation (2) ifJ and $\mathbf{K}_{\mathbf{t}}$ are the $\mathbf{n} \mathrm{x}$ npolar mass moment of inertia and torsional stiffness matrices respectively,and $\boldsymbol{\theta}$ is the $\mathrm{n}$-dimensional column vector of generalized coordinates. Thus the natural circular frequencyof the torsional system is

$\omega_{\mathrm{n}}=\sqrt{\frac{\mathbf{K}_{\mathbf{t}}}{\mathbf{J}}}$

\subsection{Steps of the FEMapplying to problems of vibration}

The FEM is a numerical technique that can be used for an accurate butapproximate solution of many complex mechanical and structural vibration problems $[6,7]$.

In this method, theactual structure is replaced by several pieces or elements, each of which is assumed tobehave as a continuous structural member called a finite element. The elements areassumed to be interconnected at joints or nodes. The mass and stiffness matricesand force vectors needed for the finite element analysis can be derived for the basic onedimensionalelements such as a bar in axial motion, a rod in torsional motion, and a beamin bending motion. The boundary conditions should be incorporated to the conditions to the assembled system matrices and equations.For clarification, an example was presented here of uniform bar considered as onedimensional element,the two end points formthe joints or nodesas shown in Figure below[8].

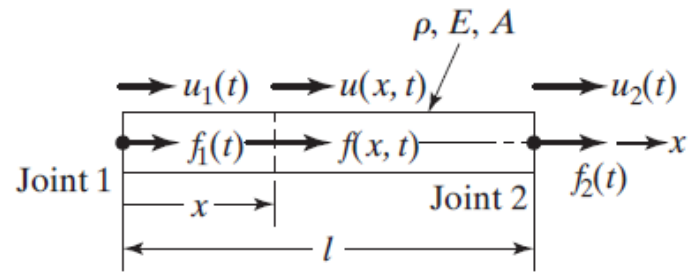

The element is subjected to axial loads $f_{l}(t)$ and $f_{2}(t)$,the axial displacement $u$ within the element is linear in $x$. The joint displacements $u_{1}(t)$ and $u_{2}(t)$ are unknowns. After several steps of derivation, the mass and stiffness matrices along with force vector can be identified as:

$[\mathrm{M}]=\frac{\boldsymbol{\rho} \mathbf{A} \boldsymbol{l}}{\mathbf{6}}\left[\begin{array}{ll}2 & 1 \\ 1 & 2\end{array}\right]$ 
$[\mathrm{K}]=\frac{\mathrm{EA}}{l}\left[\begin{array}{cc}-1 & 1 \\ 1 & -1\end{array}\right]$

And the force vector as:

$\vec{f}=\left\{\begin{array}{l}f_{1}(t) \\ f_{2}(t)\end{array}\right\}$

Where $\rho, \mathrm{E}$ are density and modulus of elasticity of the bar material respectively, $\mathrm{A}$ is the crosssectional area, and $l$ is bar length.

Most softwares using finite element techniques which included frequency analysis gives the results of all types of natural frequencies (axial, bending, and torsional) in a confusing or mixed way and not separately. This makes the sorting or isolating process of each type of natural frequencies is difficult, tedious, and consumes more time.

To facilitate this work and reduce the effort as well as the execution time of program running, a control on the selection of the type of constraints or fixtures used in the model is applied so that each of three types of natural frequencies can be found individually. Figs. 3, 4, and 5 show the types of fixtures (boundary conditions) used for axial, bending, and torsional frequencies analysis in SolidWorks.

\section{FINITE ELEMENT METHODOLOGY}

\subsection{Finiteelementmethod}

FEM simulates a solid part by splitting the itsgeometry into a number of standard shapeelements,applying loads and restraints, assign material, then computing variables of interest like deflection, stresses, ......etc. The behavior of each element is depicted by a set of equations. Just as the set of elements would be joined individuals elements are joined into a set of equations that depict the behaviors of the whole structure.Any continuous body has finite degree of freedom and its not possible to solve in this format. With the help of discretization, i.e. nodes and elements, FEM reduces degree of freedom from infinite to finite.All computations are made at finite number of points known a particular shape such as quadrilateral or triangular ....etc, is known element.To obtain the value of variable say displacement between the calculation points, interpolation function is used.The solution of any engineering problem is carried out by three methods: analytical method or hand calculations, numerical method, and experimental method or physical testing. FEM is classified under numerical method denomination. The program takes the elements which havebeen defined,puts the equationsfor each unknown value, and collects them together as equation of matrix form. Finally,solve allthese for the unknown parameters

Table 1: Material properties of Quill shaft

\begin{tabular}{|c|c|l|}
\hline & \multicolumn{2}{|c|}{ Alloy Steel } \\
\hline 1 & Yield Strength (Sy) & $620.422 \mathrm{MPa}$ \\
\hline 2 & Tensile Strength (Su) & $723.825 \mathrm{MPa}$ \\
\hline 3 & Elastic Modulus (E) & $210 \mathrm{GPa}$ \\
\hline 4 & Shear Modulus $(\mathrm{G})$ & $79 \mathrm{GPa}$ \\
\hline 5 & Poisson's Ratio $(v)$ & 0.28 \\
\hline 6 & Density $(\rho)$ & $7700 \mathrm{Kg} / \mathrm{m}^{3}$ \\
\hline
\end{tabular}

[9].
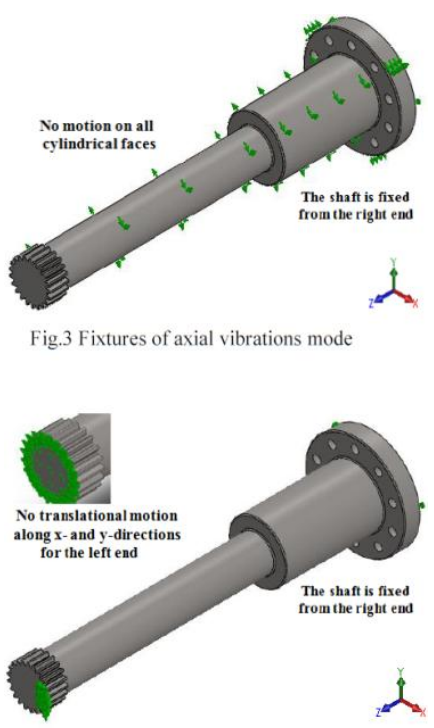

Fig.4 Fixtures of bending vibrations mode

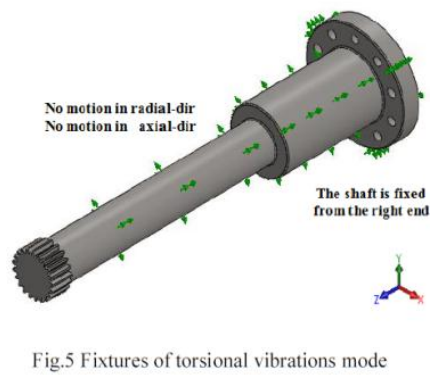

3.2 Finite element modeling and simulation 
To construct the Quill shaft model using FEM method, a trial version of SolidWorks 2011 has been used. The following steps give the modeling and simulation for the modal frequency analysis carried out by SolidWorks:

\section{Model Building}

Building a solid (3D) model of the Quill shaft using the actual dimensions extracted from Mosul gas turbine station. The solid (CAD) model and detailed dimensions of the shaft are shown in Figs. 6 and 7 respectively.

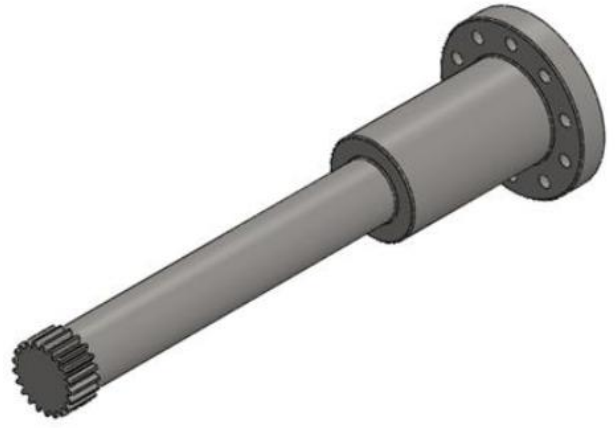

Fig. 6 Solid model of Quill shaft

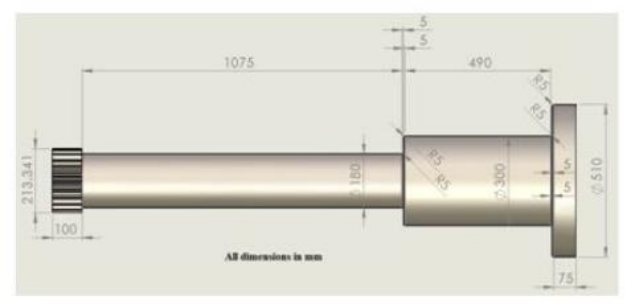

Fig. 7 Detailed drawing of Quill shaft

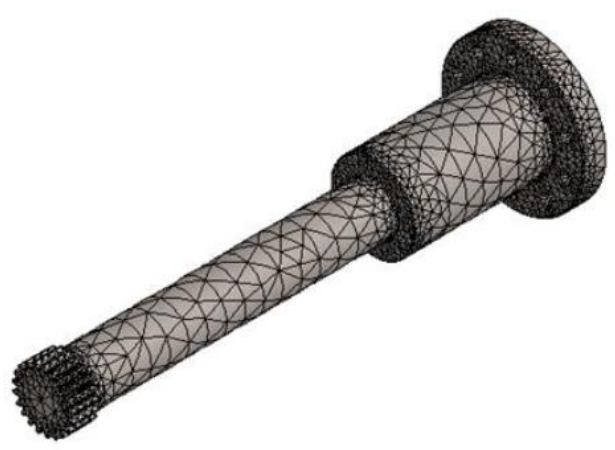

Fig.8 Mesh model of Quill shaft

\section{Material Selection}

Assign the properties of the actual material fromwhich the Quill-shaft is manufactured. These propertiesare given in Table 1.

3. Fixtures (boundary conditions) definition Refer to Figs.3, 4, and 5 again here, show the three types of fixtures used in the present modal analysis to isolate axial, bending, and torsional frequencies of Quill Shaft. A constraint means exactly zero displacement in the direction required.

\section{Model Meshing}

Results accuracy and speed of calculations are influenced directly by the type of mesh or grid used. Therefore, meshing is considered as the critical step in finite element analysis.Meshing of a geometric object represents a set of finite elements used for computational analysis or modeling. As the number of elements increased, the accuracy of results increased and the speed of calculations decreased. As a compromised solution, medium mesh rather than coarse or fine mesh has been used to obtain the accepted results, considering the computer operation ability. The type of element is solid have a minimum size of $17.32 \mathrm{~mm}$ and a maximum size of $86.632 \mathrm{~mm}$ has beenadopted. The mesh model of Quill shaft is shown in Fig. 8.

\section{Solution Form Selection}

FFEPlus is selected as the solution form as available in SolidWorks.

\section{Natural Frequency Determination}

The first $5^{\text {th }}$ natural frequencies has been calculated for each type (axial, bending, and torsion).The $1^{\text {st }}$ natural frequency is always considered the fundamental or lower value whichrepresents the closest value to the operated speed of the Quill shaft.

\section{Final Results}

The eventual results of analysis can be acquired by running the program including critical speeds and inherent mode shapes for three types of vibrations. 

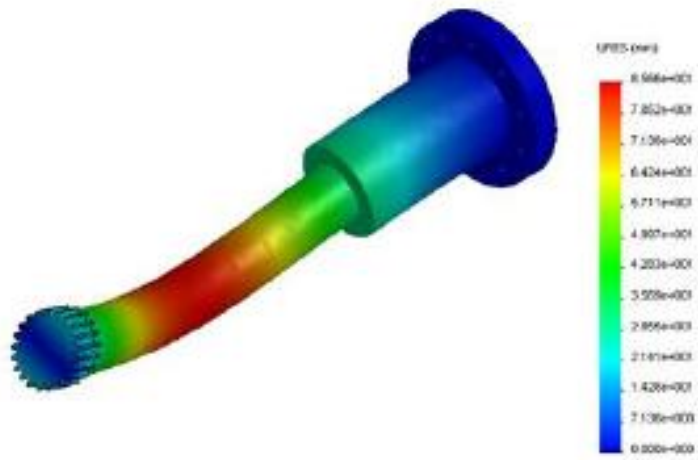

a) First mode $(277.48 \mathrm{~Hz})$
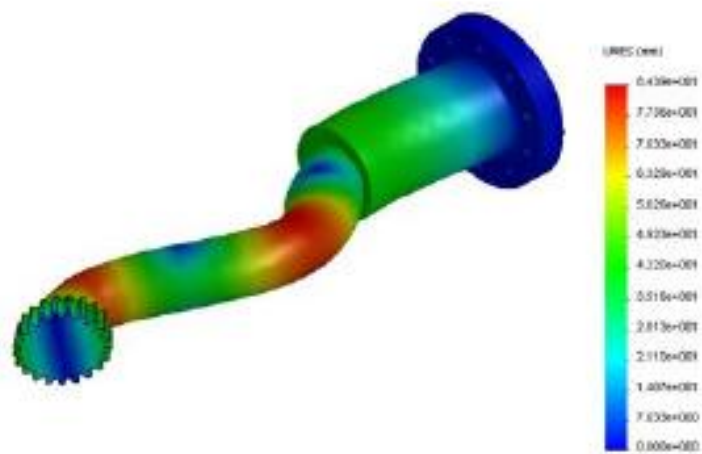

c) Third mode $(1231.4 \mathrm{~Hz})$

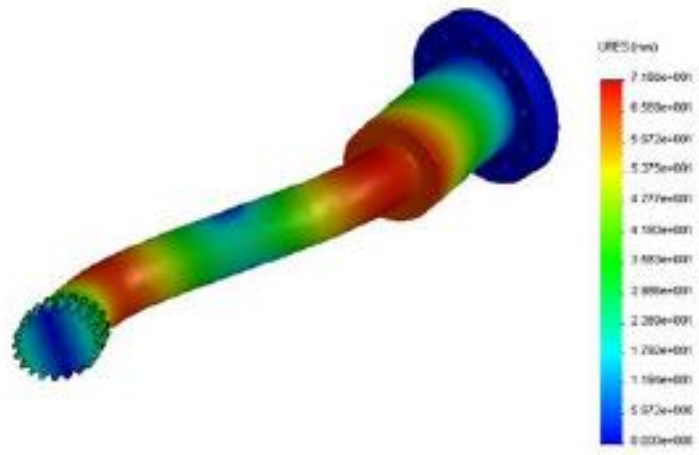

b) Second mode $(656.27 \mathrm{~Hz})$

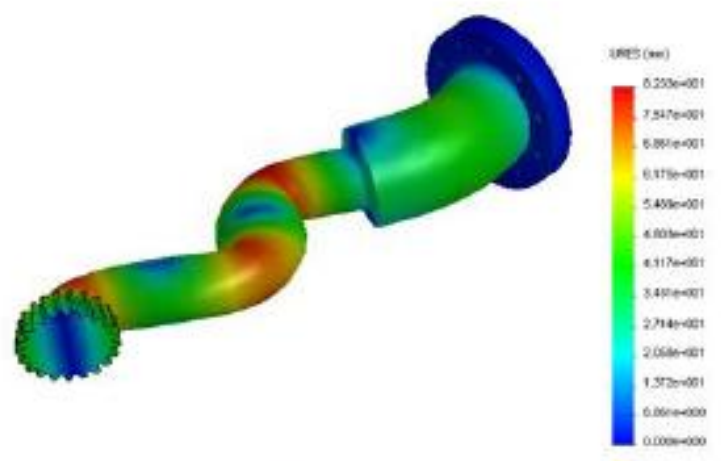

d) Fourth mode $(2019.7 \mathrm{~Hz})$

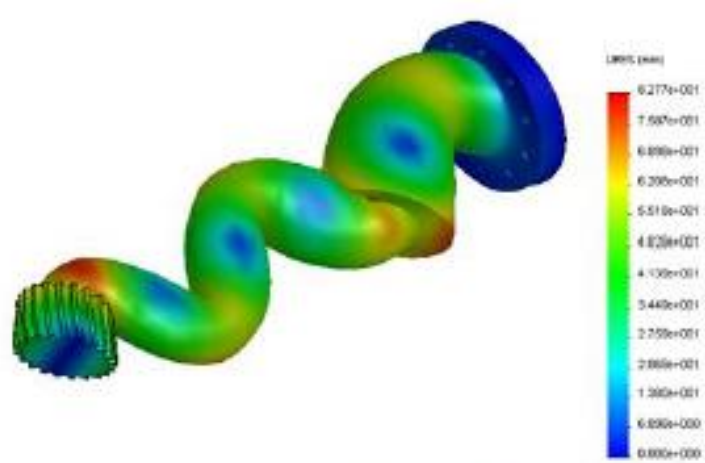

e) Fifthmode $(2681.3 \mathrm{~Hz})$

Fig.9The first five modes of bending natural frequency 


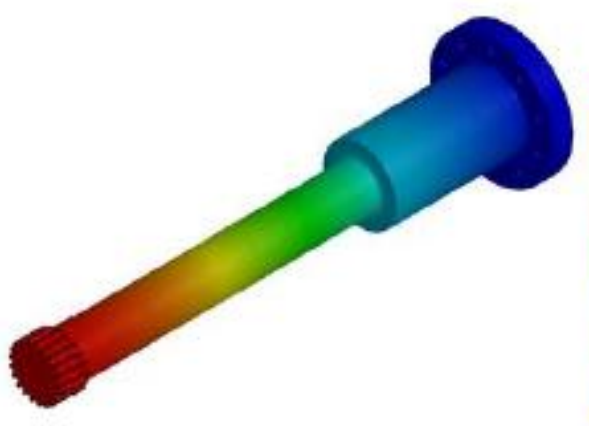

a) First mode $(1081.3 \mathrm{~Hz})$

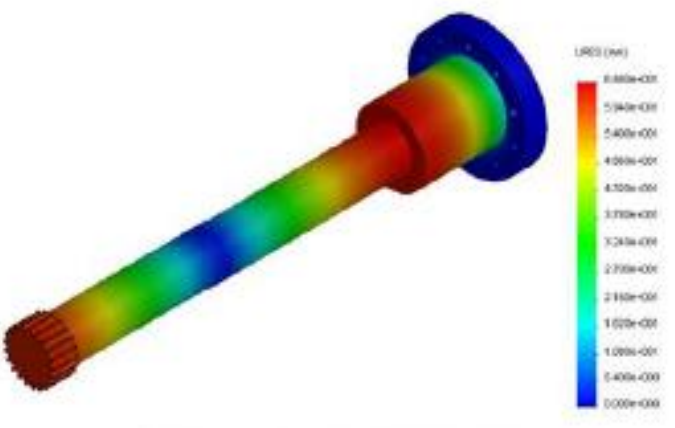

b) Second mode $(2653.3 \mathrm{~Hz})$

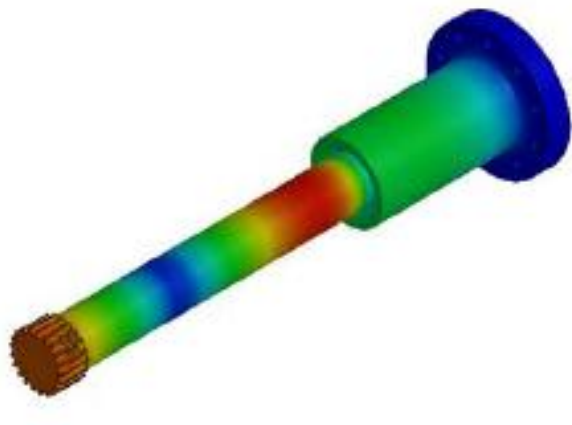

c) Third mode $(4118.5 \mathrm{~Hz})$

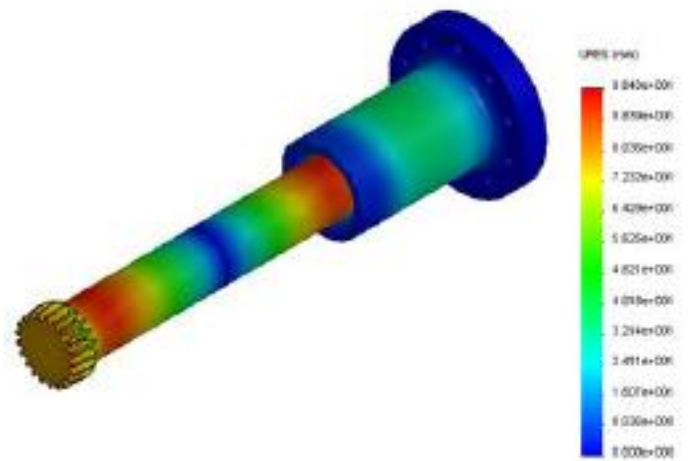

d) Fourth mode $(6262.9 \mathrm{~Hz})$

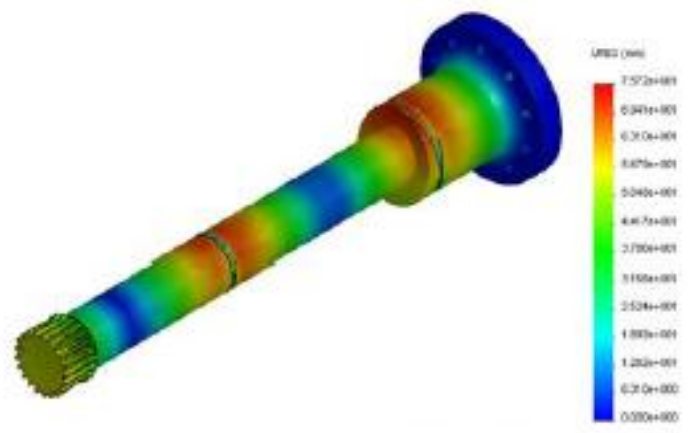

e) Fifth mode (7930.9 Hz) 


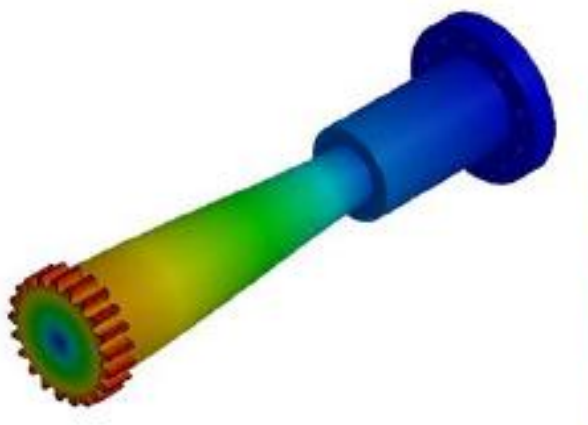

a) First mode $(654.8 \mathrm{~Hz})$

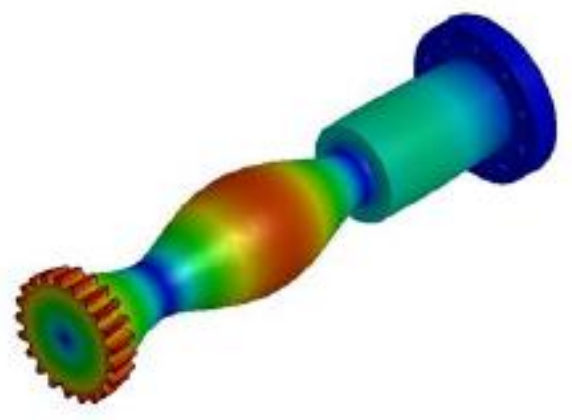

c) Third mode $(2186.6 \mathrm{~Hz}$ )

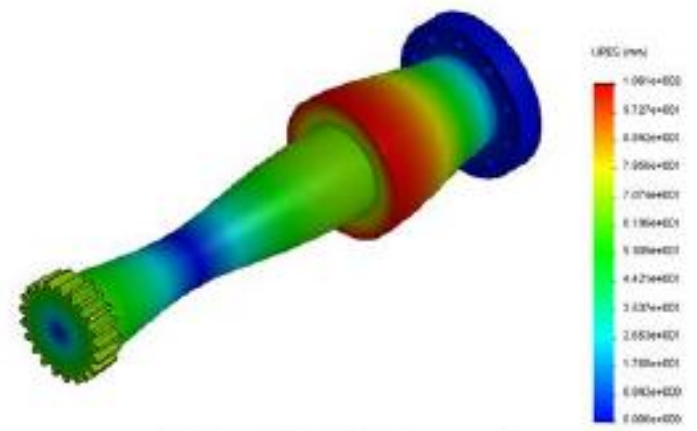

b) Second mode $(1533 \mathrm{~Hz}$ )

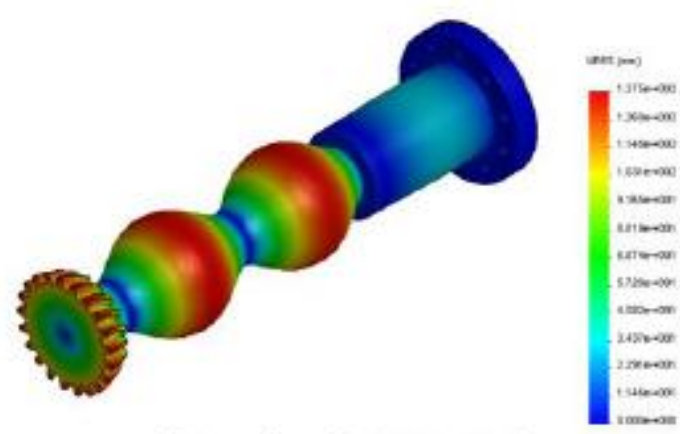

d) Fourth mode $(3532.3 \mathrm{~Hz})$

Fig. 11The first five modes of torsional natural frequency

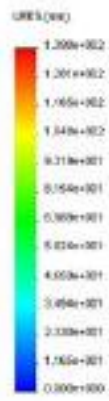

e) Fifth mode $(4592.7 \mathrm{~Hz})$

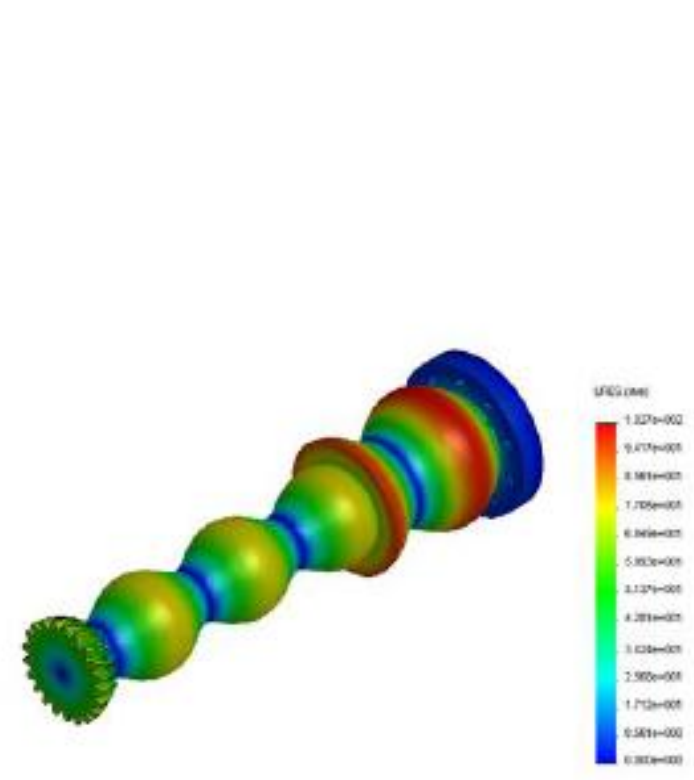




\section{RESULTS}

The vibration characteristics of Quill shaft in turbo-generator unit was obtained with modal analysis. The first five values of mode shapes of Quill shaft was found with their bending, axial and torsional natural frequencies and the deformation distribution. Each type of natural frequency has been separated in order to characterize each mode accurately and obviously.

Table2 show thebending,axial and torsional natural frequencies of the first five modes of theQuill shaft, and the inherent mode shapes is displayed in Figs. 9, 10, and 11 respectively.

The results show that the values of natural frequency seems to be increasing from first modeshape to last mode shape for all three types as shown in Fig. 12 in terms of cycle/sec (Hz), and Fig.13 in terms of revolution/min (rpm). Also, it is observed that the valuesof resonant natural frequencies are out of the rotating speed of Quill shaft in each type. The interval betweeneachnatural frequency mode is comparatively high for all three types as shown inTable2.

From the mode shapes shown in Figs. 9, 10, and 11, along with Table 3and Fig.14for maximum values of resultant displacements, it can be seen that the maximum amplitudes of shaft deformation or displacement occur at all modes for torsional natural frequencies, and the minimum amplitudes occur at second mode for axial natural frequency.

Also, it can be observed from Figs.9,10, and 11, or table 2, that the minimumvalue of resonant natural frequency which represents the nearest value to Quill shaft operating speed (3000 rpm $=60 \mathrm{~Hz})$ is the first mode of bending frequency ( $16648.8 \mathrm{rpm}=85.66 \mathrm{~Hz})$.

All types of natural frequencies (bending, axial, and torsional) are relatively high (out of the range of rotating speed of shaft, six times minimum for bending, 13.1 times medium for torsional, and 21.63 times high for axial) considered as safety margins comparing withfundamental natural frequency as reported in Tables 4, 5, and 6

\section{CONCLUSIONS}

The solid model of mechanical structure of the Quill shaft wasinserted in this work. The modal analysis using FEM with SolidWorkssimulation is offered. The three types of critical frequencies
Table 2: Results of natural frequencies of the first five mode shapes

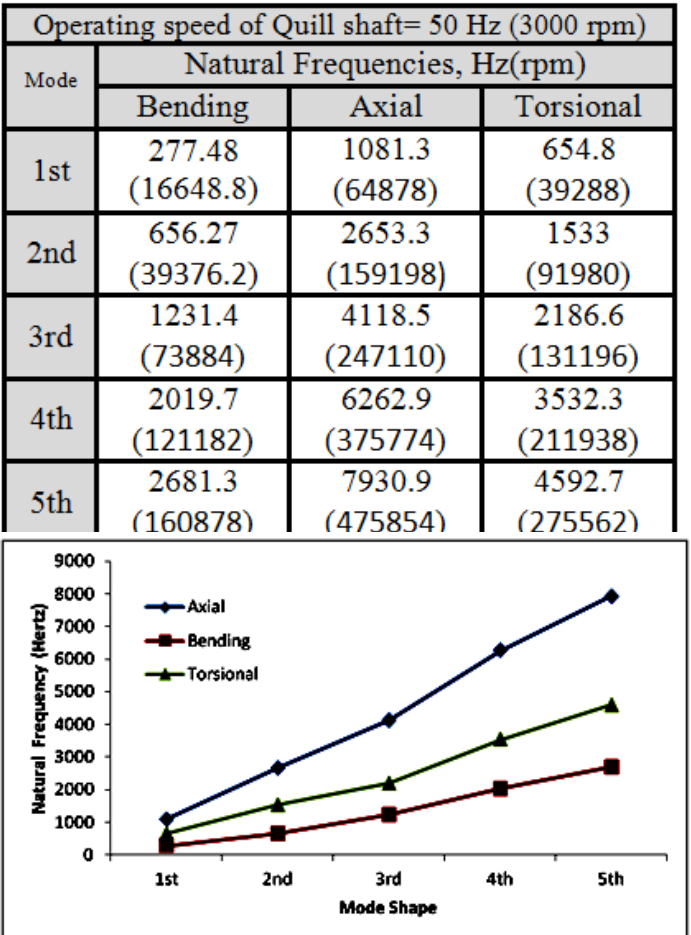

Fig. 12 Natural frequencies in $(\mathrm{Hz})$

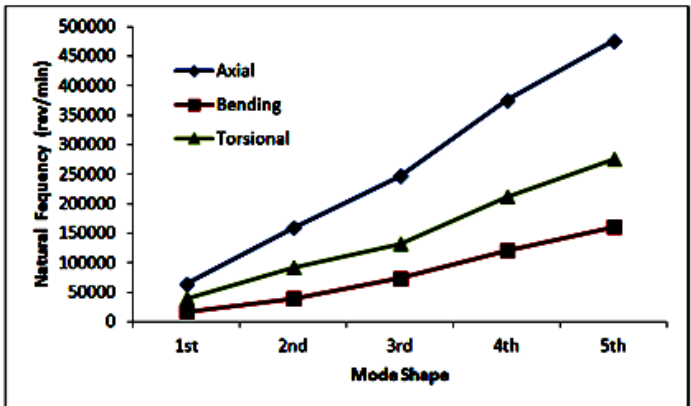

Fig. 13 Natural frequencies in (rpm)

(bending, axial, and torsional) and the inherent mode shapes of the Quill shaft are obtained.

Through the analyses mentioned above, the following conclusions have been deduced:

1) All types of natural frequencies are relatively high, i.e., out of range of rotating speed shaft $(50 \mathrm{~Hz})$, Table 2.

2) The Quill shaft is safe from the standpoint of modal analysis for all three types of vibrations (bending, axial and torsional), since the minimum value among these three types is 
almost six times the shaft operating speed, as shown in Table 4 for bending mode.

3) Forcing frequency of Quill shaft is $50 \mathrm{~Hz}$, which is very lower than of any of each three types of critical speeds. Therefore, the resonant condition cannot be happened and Quill shaft is not running at critical speed.

4) However, practically, if the generator-unit is exposed suddenly to some types of severe loading conditions, such as open circuit or unloading fault, then the speed of Quill shaft will be increasing drastically to values much more than the operating speed and may be exceeded the resonant value. In this case, the redesign of Quill shaft should be carried out.

Table 6: Safety margins of torsional mode

\begin{tabular}{|c|c|c|}
\hline \multicolumn{3}{|c|}{ Operating speed of Quill shaft $=3000 \mathrm{rpm}(50 \mathrm{~Hz})$} \\
\hline Mode & $\begin{array}{c}\text { Torsional natural } \\
\text { frequency (rpm) }\end{array}$ & $\begin{array}{c}\text { Safety margin } \\
\text { (=Torsional natural } \\
\text { frequency/operating speed) }\end{array}$ \\
\hline 1st & 39288 & 13.1 \\
\hline 2nd & 91980 & 30.7 \\
\hline 3rd & 131196 & 43.73 \\
\hline 4th & 211938 & 70.65 \\
\hline 5th & 275562 & 91.85 \\
\hline
\end{tabular}

\section{REFERENCES}

[1] S. M. Ali, Z. Y. Mohammad, and F. Q.Yahya, Estimation of Model Parameters forTorsional Vibration Analysis of a Turbo-Generator Unit with Reference to MosulGas-Turbine Station, AlRafidainEngineering Journal, Vo.23, No.2, 2015,pp. 91-116.

[2] Qing He and Dongmei Du, Modeling and Calculation Analysis of Torsional Vibration for Turbine Generator Shafts, Journal of Information and Computational Science, Vol. 7, October, 2010, pp. 21742182.

[3] Yichang Liu, chunlinTian, Tao Liu, and Fanwu Kong, Modal Analysis of Worm Gear Based on ANSYS Workbench, MATEC Web of Conferences 34, 02014, 2015.

[4] LiCheng and Hongguang Wang, Finite Element Modal Analysis of the FPD Glass Substrates Handling Robot, international Conference on Mechatronics and Automation, Proceedings of 2012 IEEE, August 5-8, Chengdu, china,2012.
Table 3: Maximum resultant displacements for all modes

\begin{tabular}{|c|c|c|c|}
\hline \multicolumn{4}{|c|}{ URES IN SOLIDWORKS } \\
\hline \multicolumn{4}{|c|}{ RESULTANT DISPLACEMENT (mm) } \\
\hline & \multicolumn{3}{|c|}{ MAX VALUES } \\
\hline Mode & BENDING & AXIAL & TORSIONAL \\
\hline 1st & 85.66 & 88.71 & 155.6 \\
\hline 2nd & 71.66 & 64.8 & 106.1 \\
\hline 3rd & 84.39 & 90.95 & 139.8 \\
\hline 4th & 82.33 & 96.43 & 137.5 \\
\hline 5th & 82.77 & 75.72 & 102.7 \\
\hline
\end{tabular}

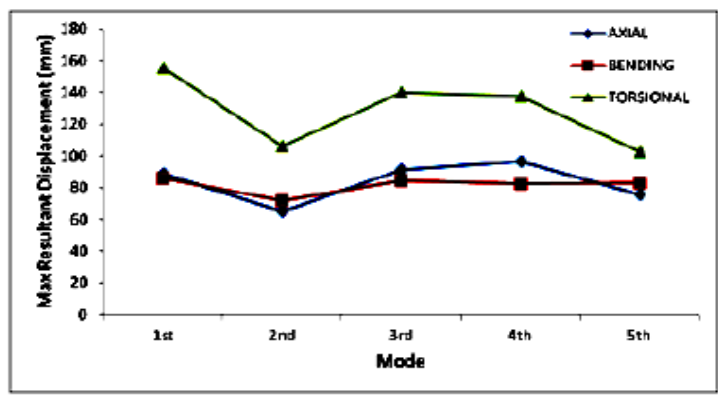

Fig. 14 Relation between maximum resultant displacements for all modes

Table 4: Safety margins of bending mode

\begin{tabular}{|c|c|c|}
\hline \multicolumn{3}{|c|}{ Operating speed of Quill shaft=3000 rpm $(50 \mathrm{~Hz})$} \\
\hline Mode & $\begin{array}{c}\text { Bending natural } \\
\text { frequency (rpm) }\end{array}$ & $\begin{array}{c}\text { Safety margin } \\
\text { (=Bending natural } \\
\text { frequency/operating speed) }\end{array}$ \\
\hline 1st & 16649 & 5.55 \\
\hline 2nd & 39376 & 13.13 \\
\hline 3rd & 73884 & 24.63 \\
\hline 4th & 121182 & 40.39 \\
\hline 5th & 160878 & 53.63 \\
\hline
\end{tabular}

Table 5: Safety margins of axial mode

\begin{tabular}{|c|c|c|}
\hline \multicolumn{3}{|c|}{ Operating speed of Quill shaft=3000 rpm (50 Hz) } \\
\hline Mode & $\begin{array}{c}\text { Axial natural } \\
\text { frequency (rpm) }\end{array}$ & $\begin{array}{c}\text { Safety margin } \\
\text { (=Axial natural } \\
\text { frequency/operating speed) }\end{array}$ \\
\hline 1st & 64878 & 21.63 \\
\hline 2nd & 159198 & 53.1 \\
\hline 3rd & 247110 & 82.4 \\
\hline 4th & 375774 & 125.3 \\
\hline 5th & 475854 & 158.62 \\
\hline
\end{tabular}


[5] S. Graham Kelly, Mechanical Vibrations: Theory and Application, SI, Global Engineering Christoper M. Shortt, 2012.

[6] O.C. Zienkiewicz,The Finite Element Method, $4^{\text {th }}$ ed., McGraw-Hill, London, 1987.

[7] S. S. Rao, The Finite Element Method in Engineering (3rd ed.), ButterworthHeinemann,Boston, 1999.

[8] S. S. Rao, Mechanical Vibrations, $5^{\text {th }}$ ed., Prentice Hall, 2011

[9] Ravikant, GopalKrishan, and MukeshDidwania, Modal Analysis of Drive Shaft Using FEA, International Journal of Engineering and Management Research, Vol.3, No.1, February, 2013. 


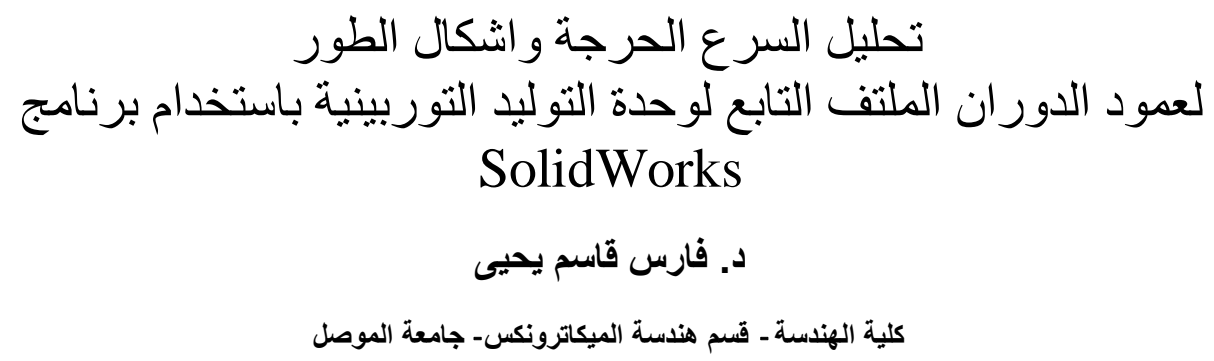

الخلاصة

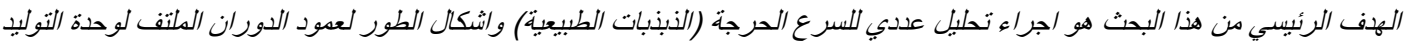

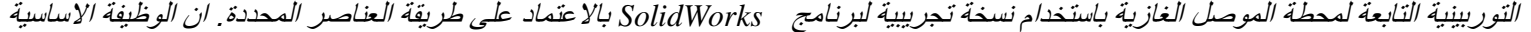

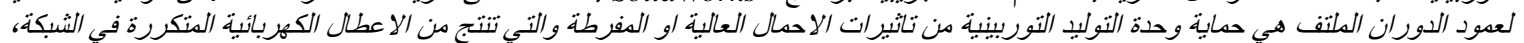

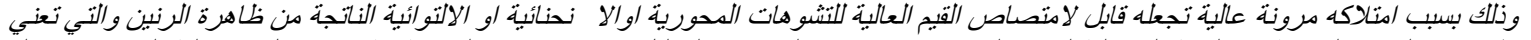

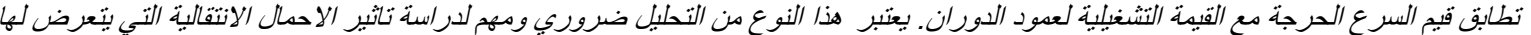

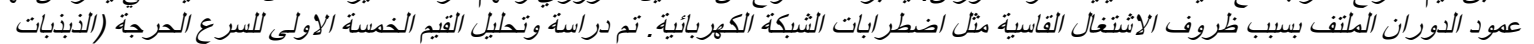

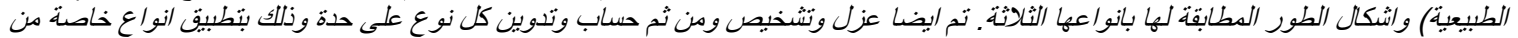

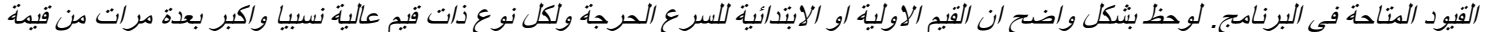

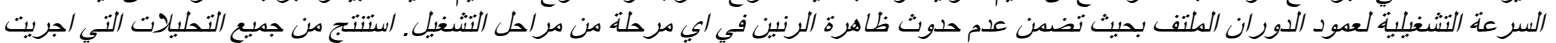

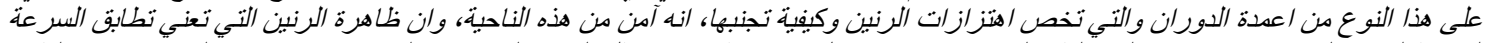

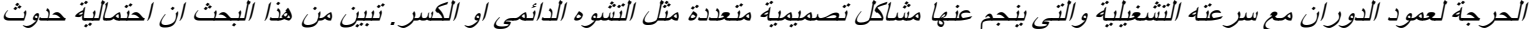

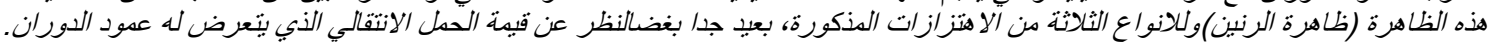

